\title{
I Wish the Bears Were Bigger: The Role of Upward Counterfactuals on Perceptions of Ownership in a Participatory Setup (An Abstract)
}

\author{
Devdeep Maity and Todd J. Arnold
}

\begin{abstract}
The US retail industry makes billions of dollars a year by engaging customers to participate in their business (design, production, delivery of goods and services); however, the psychological implications of such participation by customers have recently began gaining scholarly prominence. This paper explores the role of potent upward counterfactual thinking (the process of looking back at events and thinking about how things could have turned out better) in a participatory setup. More specifically, the role of upward counterfactual potency on perceived ownership toward the coproduced good is examined. Additionally, the role of consumer's self-assessment of participation as an antecedent to upward counterfactual potency and the moderating role of opportunity to return the product on the aforementioned are explored.
\end{abstract}

References available upon request.

D. Maity $(\triangle)$

Delaware State University, Dover, DE, USA

e-mail: dmaity@desu.edu

T.J. Arnold

Oklahoma State University, Stillwater, OK, USA

e-mail: todd.arnold@okstate.edu 